\title{
How We Know Each Other
}

Exploring the Bonds of Friendship Using Friendship Ethnography and Visual Ethnography

\section{Andrew Stevenson and Rebecca Lawthom}

\section{(2) OpenEdition}

1 Journals

Electronic version

URL: http://journals.openedition.org/anthrovision/2525

DOI: 10.4000/anthrovision.2525

ISSN: 2198-6754

\section{Publisher}

VANEASA - Visual Anthropology Network of European Association of Social Anthropologists

\section{Electronic reference}

Andrew Stevenson and Rebecca Lawthom, «How We Know Each Other », Anthrovision [Online],

5.1 | 2017, Online since 30 June 2017, connection on 30 April 2019. URL : http://

journals.openedition.org/anthrovision/2525; DOI : 10.4000/anthrovision.2525

This text was automatically generated on 30 April 2019.

(c) Anthrovision 


\title{
How We Know Each Other
}

\author{
Exploring the Bonds of Friendship Using Friendship Ethnography and
} Visual Ethnography

Andrew Stevenson and Rebecca Lawthom

\section{Introduction: Friendship}

1 This paper explores bonds that hold a particular friendship together, using a fieldwork technique that acknowledges the family-like resemblances that exists between friendship and research ties. Rather than studying individuals from afar (Fine 1994), in a style that is often called participant observation, it makes sense here to set friendship and fieldwork (with their many parallels), side by side, and to study one using practices that are common to the other. Hence, the decision has been made interrupt the tendency to study friendship from a distance, and to study friendship amongst friends, according to the dialogical ethics of friendship. The emphasis here is on researching friendship within a dialogic dynamic rather than an observational one (Bakhtin 1986).

With this in mind, the aim of this paper is to explore, using qualitative research methods that are outlined below, the nature of friendship bonds in four friendship pairs.

\subsection{Anthropologies of Friendship}

3 We will begin by locating friendship in the discipline of anthropology, where it has often stood in the shadow of kinship (Beer and Gardner 2015). While the importance of friendship bonds has been acknowledged, (Firth 1999), overt ethnographies of friendship have been "few and far between" (Coleman 2010:197). This owes something to the fact that theoretical writing in the discipline has tended to stress the importance of externally situated, coercive power relations, rather than interpersonal, leisure based relationships (Beer and Gardner 2015). Another reason for the backgrounding of friendship in anthropology may be that theories arising from analyses of economic relations or kinship practices may not have be the ideal tools for apprehending meaning that emerges from everyday practices of acquaintance or affiliation (Paine 1969). 
4 In this paper we argue, using evidence from fieldwork conducted in the UK, for an exploratory, less theory driven orientation to friendship (Leyton 1974), in contrast with functionalist approaches to kinship that characterise early anthropology (Paine 1974). We also argue that an anthropology of friendship may be compatible with kinship studies, considering similarities in their practice, nature and characteristics (Desai and Killick 2010, Fausto 2012). One author who does locate friendship closely to kinship is Pitt-Rivers (1973), who assimilates friendship as a form of kin relation, arguing that both have at their core a submersion of self-interest for the sake of others. Pitt-Rivers highlights the heart's role in both these realms, in effectively extending the self into others. The obligations of kinship and friendship practices are regarded in this work as being part of the norms of societies in which these extended selves are embedded. As we demonstrate with the friendship pairs from the current study, friendship bonds are not merely the business of two people, but reflect wider networking affiliations. Marshall (1977) also regards motivations or commitments of kin and friendship as part of wider norms of obligation that are central to Trukese society in Micronesia. Equally, the friendship pairs we explore here are engaging in relations that cannot be seen as detached from the webs of relations of which they form a part.

5 Another dichotomy emerging from friendship studies is the debatable separation between relations that are private, informal and voluntary, as friendships are typically constructed (Silver 1989), and those that are public, contractual and societally sanctioned, as kin or economic relations tend to be. One might question these distinctions. We would like to suggest that the domain of private, voluntary relations is "a distinctive creation of the impersonal order central to modern economies and polities" (1997:44), and is thus not a separate realm of human relations that is unconnected to societal institutions (Silver 1989). As we shall assert in the research presented here, friendship pairs are often thrown together in scenarios that are inseparable from choices about work, parenting and even ageing.

6 A third question arising from a wider disciplinary perspective is that of the cultural particularity about friendship, which demonstrably has a shifting meaning across cultural settings. Carrier (1999) discusses a so-called Western view of friendship, hewn from internalised "spontaneous and unconstrained sentiment" (1999: 21), suggesting that Western terms of reference for relating to the self may not be appropriate for Melanesians, who understand relations in the context of kinship and situated contexts. Carrier's observations about Melanesian friendship should be viewed through the comparative lens of observations presented here, deriving from the UK. And yet we could question the implication that the autonomous, independent self is a Western phenomenon. It has been reported that Mapuche friendship relations reportedly exist between autonomous individuals with individual sentiment playing a strong part (Desai and Killick 2010). Likewise, Killick's (2009) Peruvian work with the Asheninka highlights "the importance of self-sufficiency and of personal independence and autonomy" in the formation of crucial social relationships (2009: 705). We will see in the work presented here, even in the UK friendship relations are embedded in broader interpersonal networks.

7 In this paper, we intend to contribute to an anthropology of friendship by highlighting elements of friendship practice that reveal its parallels with more familial relations, and which show friendship bonds as being inseparable from other forms of interpersonal relations. 


\subsection{Varieties of Friendship} just friends". Werking (1997) deems friendship to be a more fragile, disposable social bond than that which exists between siblings or spouses. A friendship is often based as much on something frequently done with another person (Owton and Allen-Collinson 2014, Tillman 2015), or on a shared belief, rather being purely based on an emotionally binding strength of affect.

Friends come and stay together primarily through common interests, a sense of alliance and emotional affiliation. (Tillman 2015:2).

Perhaps because of the lack of an innate or familial bond, friends have been referred to as families we choose (Roseneil and Budgen 2004), or elective kin (Pahl and Spencer 2004), and can differ in type and vary in levels of intensity (Pahl and Spencer, 2004, Heaphy and Davies 2012). Some might be referred to as simple friendships, being based on sharing a single activity (work, leisure, belief, political affiliation). Partners who form simple friendships may rarely meet outside of these contexts, leading to the use of defining terms such as 'work-friend'. Elsewhere intimate relationships have been painted as emerging from friendship-defining, unifying struggles in the context of activism and feminism. Shepard (2014) stresses ways in which friendships can emerge from a desire for social change, with bonds of friendship being the glue that holds activist work together.

Besides being practice based, elsewhere friendships have been recognized as multistranded affairs, based on affiliative bonding as well as a specific practice or cause. Heaphy and Davies conducted ethnographic interviews (Spradley 1979) in an inner-city housing estate with friendship pairs, to investigate the vicissitudes of friendship bonds. Here, one respondent reflects on such a multi-stranded bond

Friendship for me has several different levels. The best are 'close friends' - those people who, usually, I have known for a long time, and with whom I have a shared history. (Heaphy and Davies 2012:315)

In multi-level relationships such as these, interconnectedness can comprise experiences that include "support, reciprocity, commonality, a feeling of kinship and/or being familylike" (Heaphy and Davies 2012:315). Friendship goes beyond dependence on a single, defining practice or belief.

Besides illustrating the multilevel nature of friendship, their data also revealed that the interconnectedness of friendship extends beyond these pairs, into community networks. Participants revealed that these bonds were part of a broader interconnecting webs of friendship relations, showing friendships to be frequently set within wider occupational, leisure, or neighbourhood groups. It has also been suggested that the influence of these shared histories varies across differing social groups. For example, traditional workingclass friendships have been seen to thrive on shared experiences from school, work and/ or family life. The sharing of such formative experiences solidify arguably yields sustained relationships that form around values of community and continuity (Whyte 1993, Young and Willmott 1961). These varieties of friendship highlight the rootedness of 
interpersonal bonds in shared experience, yielding relationships with kin-like features, such as obligation, care, longevity, and the interdependency of wider webs of relations.

Yet whilst some friendships may endure in ways that family bonds are expected to, it is common for friendships to coalesce around more individualistic pursuits, such as nightlife and leisure time activities that provide a

... platform for making a personal 'impact' and achieving a sense of significance and distinction in night-time leisure cultures. (Winlow and Hall 2009:106).

We have so far learned that friendship takes many forms, serving a variety of functions. They can run deep, along multiple channels and beyond immediate pairs. They can rely on specific, formative activities. They can also be particularly intense when at times of transition, like bereavement, birth, coming out (Cherry 1996).

Yet whilst rooted in incremental shared experience, it is equally important for friendship to remain relevant in the present (Shepard 2014). Friendships are more binding when incorporated into present, mundane routines and broader webs of obligation or activism, when "We share the same interests and sense of humour and we meet on a regular basis" (Heaphy and Davies 2012:320).

This opening section focuses on anthropologies, varieties and characteristics of friendship. We have seen them to be comparable to kinship, differing in levels, part of larger networks, steeped in obligation, memory, practice, and fluctuating in strength. In this paper, we will present visual-based research to argue that friendship bonds are not only based on liking, but on longevity, regular practice based contact, and on embeddedness in wider social relations.

Let us end this introduction by considering a characteristic of friendship which is especially concerning for ethnographic researchers; its parallel with the research encounter itself. Friendship shares forms of relational entanglement with ethnographic fieldwork. The challenges of operating intimately with participants have been highlighted as ones which engage us both at professional and human levels (Powdermaker 1967). The dual obligations of retaining the gaze of a social scientist whilst also conducting close interpersonal relations present a unique dilemma (Ager 1996). Friendship and ethnography both involve entring into another's space, negotiating roles, incrementally deepening of ties, and learning new codes of interaction (Tillman 2015). Friendship, like fieldwork, raises the dilemma of "getting out" (Iverson 2008) when the time has come to end the entanglement. These dilemmas are played out within webs of significance that permeate friendship communities and the field (Geertz 1973).

In view of these parallels, this paper explores bonds that hold friendships together relationally, using fieldwork techniques that acknowledge the family resemblances that exist between friendship and research ties. Rather than by studying individuals from afar (Fine 1998), it makes sense here to set friendship alongside fieldwork; to study one using practices common to the other. In qualitative research, there is a constant decisionmaking process about how closely to work with, to know, the subject (Fine 1998). Here the decision has been made to study friendship among friends, according to the dialogical ethics of friendship. The emphasis here is on researching friendship within a dialogic dynamic rather than an observational one (Bakhtin 1986).

The aim of this paper is to explore, using two complementary qualitative research methods, the nature of friendship bonds and practices, in four friendship pairs. 


\section{Method}

21 The current research project was conducted using (i) friendship ethnography (Tillman 2015), incorporating traditional ethnographic methods (interviewing, participant observation), and (ii) visual ethnography (Pink 2007).

\subsection{Friendship Ethnography}

Friendship ethnography is a variation on traditional methods of participation (Langdridge and Hagger-Johnson 2013). It involves adopting the values, practices and ethics of friendship in a research context. In the practice of friendship ethnography, traditional methods of fieldwork (interviewing, observation) are set alongside friendship building practices; conversation, everyday involvement, compassion, generosity, and 'hanging out' (Tillman 2015). For example, Cherry (1996) conducted an ethnographic account of a community of people living with AIDS. As well as collecting data through interviews and photography, the researcher engaged in friendship practices with participants. Together, researcher and researched played sport, watched TV, attended and arranged funerals, made hospital visits, all of which added emotional and relational layers to the relationship. Through this process, the relational dynamics of researcher, participant, and friend grew increasingly entangled. Tillman (2015), in her exploration of an LGBT community, also came to know her respondents interpersonally and culturally, achieving the opportunity to give compassion and devotion, to experience them emotionally and spiritually. The research involved simultaneously talking, sharing activities, exchanging material, writing and exchanging views. Thus, researcherfriendship roles wove together, each one deepening the other. Participants became (and remained) family. Relationships extended through multiple dimensions of life.

In researching friendships, we consider it important to connect to our participants (Owton and Allen-Collinson 2014). In further interrogating the nature of the relationship between researcher and participant, we argue that whilst all participants may not be considered as friends, we cannot afford to treat them as distant others either.

Through this process, the relational dynamics of researcher, participant, and friend grow increasingly entangled. The nature of the relationships override that of observerobserved, taking us towards a methodological variation on participant observation. A slow pace of research is ideal for such projects. They develop over months or years (Cherry 1996) and often rely on serendipity, rather than outright planning (Rivoal and Salazar 2013), very much as friendships themselves do. The friendship ethnography model is less utilitarian than the researcher-participant relationship that prevails in traditional ethnographic work. It reflects the practice of a more person-centred, holistic citizenship. Friendship ethnography is used to get to know others in meaningful, sustained ways (Fine 1994, Tillmann-Healy 2001, Owton and Allen-Collinson 2014). It can disrupt traditional unequal power relations between researchers and participants, reducing hierarchical separations. It is based around relationships that are dialogical, empathetic, caring and very often (as in the present project), existing.

This embedded research approach does not map neatly onto the traditional notions of ethical protocols that presuppose a linear notion of research, in terms of access and exit routes. Whilst ethical practices were adhered to for the present study, according to the 
ethical practices recommended by our university and our professional body, the nature of the friendship ethnography researcher-participant dynamic calls for something else. Friendship ethnography draws on an ethics of care (Gilligan 2008, Held, 2006). Eschewing the idea of a universal deontological set of principles, an ethics of care recognizes and privileges relational ethics. Relationships with participants are recognized as developing, ongoing, enduring and often pre-existing, needing attention to be paid to the context in which they are made, researched with and made sense of. Added intellectual interest brings something more to a relationship, on top of affection, emotional support, or shared practice. Participants who know that a researcher cares and has an emotional link, are more likely to know that their confidences will not be breached, and that their interests will be honored. Similarly, when research is an endeavor approached in the spirit of friendship, emergent outputs can additionally benefit participants in terms of self-understanding and a deepening of a sense of friendship between those involved. Thus, according to this ethics of care, the present study was conducted according to friendship values, according to which the participants themselves might learn about their own friendships, as well as we as researchers learning about them.

The four friendship pairs who feature in this project are not only friends with each other. This research is about friendships, and it occupies spaces within and across friendships. In qualitative research, there is a constant decision-making process about how closely to work with, to know, the subject (Fine 1998). Here the decision has been made interrupt the tendency to study friendship from a distance.

\subsection{Visual Ethnography}

As well as using friendship ethnography, the present study was conducted through the making of an ethnographic documentary film about friendship pairs. The justification for using this visual element reflects a keenness to demonstrate the nature of friendship ties in ways that that can be seen and heard in a spatial context, rather than merely reported textually, through interviewing.

Friendship pairs regularly practice their bonds on daily, weekly, bases, often through occupational or leisure time activities. The nature of such friendships may not be explicable in conversation or available for capture through just talking. It is argued here that simply asking for participants' accounts using interviews will not enable us to gain full access to quotidian friendship practices. This contention informs our use of visual ethnography (Pink 2007). As well as hearing the accounts of the eight participants in this study through the use of interviews, the use of documentary film enables us to conceive of participants' thoughts and actions as more than textual (Pink 2007). Adopting this method enables us to appreciate other forms of knowledge, including imagery, sound, physical settings, dwellings, implements and other possessions that surround our participants. Using film as well as interviews grants access to phenomena wherein so much (practices, silences, routines) is unspoken, acted out. The use of visual and auditory methods helps us to see and hear what people do and where they do it and have those experiences put into words for us.

We are accustomed to regarding thought as something resembling language - the mind speaking to itself or, as dictionaries put it, a process of reasoning. But our conscious experience involves much more than this kind of thought. It is made up of ideas, emotions, sensory responses. (MacDougall 2006:2). 
ued here that the use of film to accompany qualitative interviewing can add to the present literature on ethnographies of friendship (Pahl and Spencer 2004, Heaphy and Davies 2012, Owton and Allen-Collinson 2014, Tillman 2015) by offering a multisensory portrait of relational practices, thus complementing a growing body of work that is oriented towards reported verbal accounts. Through this research project we aim to explore the nature of four friendships as they are experienced, and the practices that bind them, by hearing participants' accounts, and by seeing and hearing their friendships in action.

\subsection{Participants}

For the present research project the lead researcher worked with four friendship pairs (one including the lead researcher) over a period of twelve months intensively. The researcher's relationship with the pairs pre-existed and outlasted this time. Time was spent interviewing, filming and joining in with the practices that occupied and cemented each friendship. Our time together extended to activities as diverse as sharing meals, drinking tea, Scottish country dancing, cycling, engaging in community activism against food poverty, and car sharing. The fieldwork yielded traditional field-notes, transcripts, still photographs, as well as a thirty-minute documentary film, How We Know Each Other (HWKE), presented in four 7-8 minute 'chapters'. Each chapter is devoted to a friendship pair. A trailer for the film is available online.

This media file cannot be displayed. Please refer to the online document http:// journals.openedition.org/anthrovision/2525

Link: https://vimeo.com/130013072

The full length film has been publically screened in the UK and in Slovenia, in ethnographic film festival contexts. All four friendship pairs fully consented to taking part in the research and to appearing in the resulting documentary film. They have also consented to the use of their first names in this paper, and in the documentary film.

\section{Anne and Louise}

e and Louise (Chapter 1 of HWKE) met through attending a yoga class seventeen years ago. Soon after meeting they began to practice yoga together twice weekly in each others bedrooms, which they rearrange for the purpose. Anne and Louise were filmed during their yoga practice and interviewed over dinner, cooked by the lead researcher, at Louise's house. The lead researcher has known Anne and Louise for over fifteen years and has practiced yoga with them during this period of acquaintance.

Amy and Laura (Chapter 2 of HWKE) met through working together at a UK university, in an office. They began car sharing, taking it in turns to drive, a year before our research project began. Their experience of commuting together in a small, shared space is the focus of our research here. Amy and Laura were filmed and interviewed in their cars during one week of commuting to and from work. The lead researcher has known Amy and Laura for over two years, through an employment context. 
and Barbara (Chapter 3 of HWKE) met seven years ago at a local recreational folk music group, and together they provide musical accompaniment for a weekly Scottish Country Dancing class (Ishbel on fiddle, Barbara on keyboard). They rehearse every Monday at Barbara's flat. They were filmed and interviewed during rehearsal and at their dance class. The lead researcher met Ishbel and Barbara through a mutual friend and joined the Scottish country dance class during the fieldwork period. Research with Ishbel and Barbara was conducted during rehearsals and during their class.

\section{Andrew and Zara}

Andrew (the lead researcher) and Zara (Chapter 4 of HWKE) met two years ago through volunteering at an anti-food poverty charitable organization. They share the weekly, twohour task of collecting surplus food from supermarkets and transporting it, by bicycle, to a community kitchen. A research assistant filmed and interviewed Zara and Andrew during and after voluntary work sessions.

\section{The Nature of the Friendship Bonds}

41 The subsequent sections report emergent themes which were derived from thematic analysis of interview transcripts (Braun and Clarke, 2006), that illustrate the nature of the friendship bonds and practices that were evidenced from working with the four friendship pairs. These themes are presented here using quotes from interview transcripts, film stills, reference to the film itself and its soundtrack, which readers can refer to online. The visual materials presented and referred to here are to be considered as part of the data itself, to supplement and enhance the interview transcripts and quotes. Similarly, reference to the soundtrack to the film is considered to provide additional evidence for the more than textual nature of the friendships featured here (Butler 2007, Howe 2005)

\subsection{Friendships as Practice}

42 Friendship ties are often predicated on activities or practices that bring people together, rather than on mere affection or personal empathy (Tillman 2015). We may like our friends, but liking alone may not be enough for friendship. The four friendships featured here are all dynamic affairs, formed as much by doing as by liking. Three of the four pairs met through the very practice that prevails in the research; yoga, music, volunteering:

Louise: We met through the yoga didn't we and we just started doing it, and then after a while it just became a habit.

The exception, Amy and Laura, already worked together before sharing their commute but became closer friends once they took this step. Sharing a car, away from the hurlyburly of the shared office, enabled them to deepen their friendship:

Amy: The car sharing is an added opportunity to talk about our job and other things that aren't related to work in a closed space we haven't necessarily got at work.

The dynamic, practice-based nature of these four friendships facilitates forms of communication that go beyond 'chatting', as Anne puts it: 
Anne: We've spent so much time together but most of that time has been spent communicating with each other in a very different way to sitting chatting,

Levels of communication offered by these friendship practices are multisensory. Barbara heralds the power of music to communicate at a level that transcends words:

Barbara: There's something about music that gives you almost a telepathy attimes. It's such a wonderful way of communicating.

Friendships and the practices through which they begin and thrive are not easily separable, as Zara explains:

Zara: The best friendships that I've had are ones where you work on something together. The idea of just becoming good friends simply because you hang out or go to the pub doesn't make much sense to me.

47 As well as being illustrated by participants' quotes, the practice-based nature of these friendships is evidenced on film, through embodiment and through the senses. Figure 1 shows a still taken from a long sequence in which Louise and Anne lay together in silent relaxation, concluding their practice. Over half of the duration of Chapter 1 of the film features the pair engaged in wordless, yet communicative yogic practice. Similarly, for much of Chapter 4 we see Andrew and Zara wordlessly cycling together, moving in synchrony (Figure 2).

Figure 1. Anne and Louise

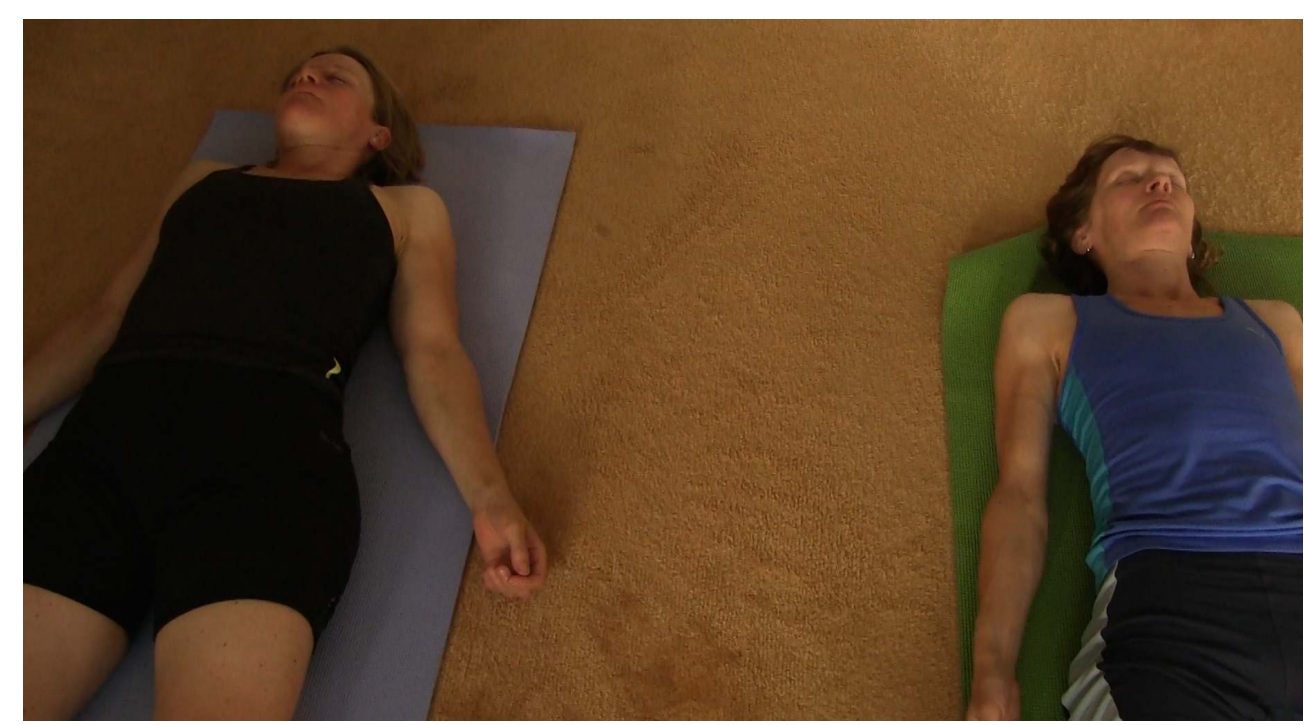

Anne and Louise practising side by side in silence

Photo by Andrew Stevenson 


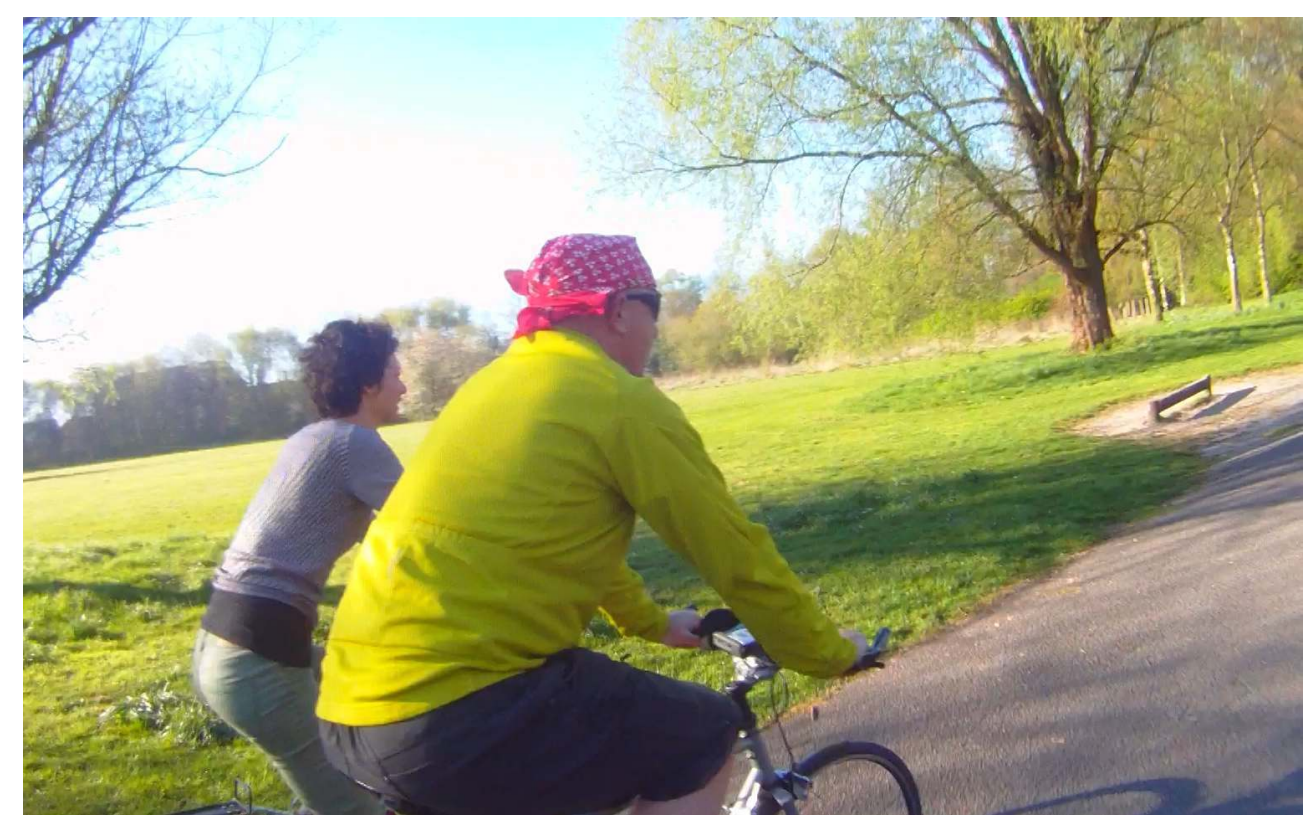

Andrew and Zara cycling together

Photo by Ines Ponte

The film's soundtrack further demonstrates the importance of non-verbal friendship practices for strengthening bonds. Listen, for example, to Amy and Laura laughing along to their favourite radio show whilst driving to and from work (Chapter 2). Listen too to Barbara and Ishbel playing traditional Scottish music together, doing friendship through sound (Chapter 3).

These prolonged 'friendship doing' sequences are central to HWKE. They demonstrate the importance of practice, embodiment and synchrony for these four relationships, as well as the depth of communication without speaking that each of these bonds thrives on. Becoming acquainted through doing, getting to know one another by communicating in ways that transcend conversation, gave the project the title for the resulting ethnographic documentary film: How We Know Each Other. These friendship practices yoga, music, commuting, cycling - are literally how these pairs of people know each other and enact friendship.

\subsection{Friendships as Suffuse Bonds}

The varying strengths and degrees of friendships are illustrated by the observation that some relationships offer more than (and are not limited to) a shared activity (Pahl and Spencer 2004). Beyond the practice-based relationship, multi-stranded friendships are suffuse affairs. Intimate pairs nest within wider networks of acquaintance (Heaphy and Davies 2012). These wider networks may also owe their existence to the practices upon which the friendships thrive. Barbara and Ishbel came together originally through a network of folk musicians, which was established before they opted to meet regularly as a duo:

Barbara: Tricky to pin down the first time we met because we were playing with the same group where you get to know each other rather gradually. 
Louise and Anne's yoga based friendship arose within a wider community of yogis:

Anne: I seem to remember there was a workshop that we went to and we went off to that café for a break. We must have arranged it from there really.

52 Amy and Laura became acquainted through their wider occupational community. They work in a large shared office. Within that network they have created a smaller, shared, mobile space where their friendship practice thrives. The car offers levels of communication that are unavailable at work:

Amy: It's definitely easier to talk in the car. We have to keep the volume down a bit in the office and you're very aware that there are several people around you.

Suffuse friendships operate within larger networks of practice, such as recreational and occupational communities. Another manifestation of the suffuse nature of friendships is their multidimensional nature. Whilst they may coalesce through shared practice, these friendship pairs also afford longevity, shared histories and affective support. Sharing ups and downs, being there during difficult times, offering companionship, these friendships can offer wellbeing in ways that go beyond the requirements and benefits of the practice that lies at their heart. Yet whilst the practice might maintain the bond, the friendship offers more than regular practice. Affectively, it brings companionship, stability and support amid the vicissitudes of life. For Laura, for example, the morning commute raises the spirits and helps her manage her early morning mood:

Laura: Some mornings I'm a bit grumpy and I just want to stew in my own grumpiness but I like picking up Amy because she always cheers me up, with something.

During and after Anne's three pregnancies, doing yoga with Louise offered an opportunity to get back to normal life:

Anne: Well we didn't completely stop, did we? I maintained it for a little while and then I'd stop and then I'd gradually come back so we'd have a gently return.

Louise: Every time you had a child you swore blind you'd never get back to where you were with it, and lo and behold, two months later we were firing again.

When Zara was asked why the weekly pick-up was better with two people she explained the mood enhancing power of companionship:

Zara: When you're on a journey and experiencing lots of novel things it's quite nice to have a bit of banter about it. Doing it on your own it just feels like you're going from one supermarket to another and you don't really enjoy all the moments in between.

We argue these friendships are doubly suffuse; they are nested in wider communities; they are affective and supportive. Bonds here seem to traverse the everyday practices of travelling, cycling and the biographical disruption of motherhood.

\subsection{Friendship Routines}

57 Arguably, multilayered friendships that revolve around shared practices are more adhesive still when they are acted out as part of a regular routine (Heaphy and Davies 2012). Regular, weekly or even daily meetings demonstrate the importance of the mundane present in the maintenance of friendship. This complements the importance of the shared pasts that were discussed in the previous section. 

place every Monday and Tuesday evening; the former a rehearsal for Tuesday the dance class. Louise and Anne share a routine for their meetings, and have done for over seventeen years:

Anne: We've always maintained it on a Sunday and I think for me there must be something about being brought up Catholic and going to church on a Sunday.

Andrew and Zara meet every Wednesday for their early morning pick-up:

Zara: It was our anniversary not so long ago. We've been cycling together for a year and a bit and you've barely missed a Wednesday.

The daily, weekly, annual rhythms of these friendships add the weight of the present to their accumulated longevity. The mundane regularity of practising friendship together binds affective bonds and prompts the occasional thought about what might happen if these routines should for some reason cease. Here, Louise and Anne dare to contemplate their friendship without the routine of yoga:

Anne: The yoga is the way we have connected and that's a big part of both our lives.

Louise: I can't imagine our relationship without the yoga. I can't imagine just knowing you and not doing the yoga with you.

61 Ending the routine would mean the end of a large part of the relationship. It would also constitute an unwelcome interruption to a weekly cycle, bringing about what Heaphy and Davies (2012) refer to as a detrimental effect on daily living.

\subsection{Friendships in Improvised Places}

During fieldwork it often emerged that friendship bonds were being enacted in improvised spaces that were designed for other purposes. The pairs were 'making do', transforming bedrooms, living rooms and cars into meaningful friendship places. Barbara's living room is transformed into a rehearsal room each week. Laura and Amy's cars are places of reflection and confiding. Here, Anne explains how she and Louise ritually turn their bedrooms into yoga spaces:

Anne: You need a reasonable amount of space, but it does mean preparing the space, which is fine. I quite enjoy preparing the room because it's all part of the ritual.

Friendship spaces are performed and transformed into being, becoming endowed with additional meaning through repetitive ritual (Cresswell, 2004). Through regular practice, the pairs generate shared friendship narratives that are inseparable from the improvised spaces where they are played out. Louise reflects here on the longevity of her bond with Anne as a function of the time they have shared on the mat space:

Louise: I think we've been doing it seventeen-eighteen years. So that's 700 weeks, two hours a week; 1400 hours. That's a lot of time on the mat.

Narratives emerging from spaces that are shared, especially by female friends, have been referred to as containment stories (Hanson and Pratt, 1995). These stories emphasise the role of shared proximity in the production of relational experience through shared bodily practice (Green, 1998). Hanson and Pratt (1995) note the potential for female friendships for transforming spaces into sites of resistance and aspiration 
"Gendered identities, including aspirations and desires, are fully embedded in - and indeed inconceivable apart from - place" (Hanson and Pratt 1995:18). nature of these friendships. Chapter 1 of HWKE begins and with Louise gradually transforming her bedroom into yoga practice space in readiness for Anne's arrival. It ends with her restoring her bedroom. In Chapter 3 we see Barbara's living room transformed into a music room (Figure 3).

Figure 3. Barbara Ishbel

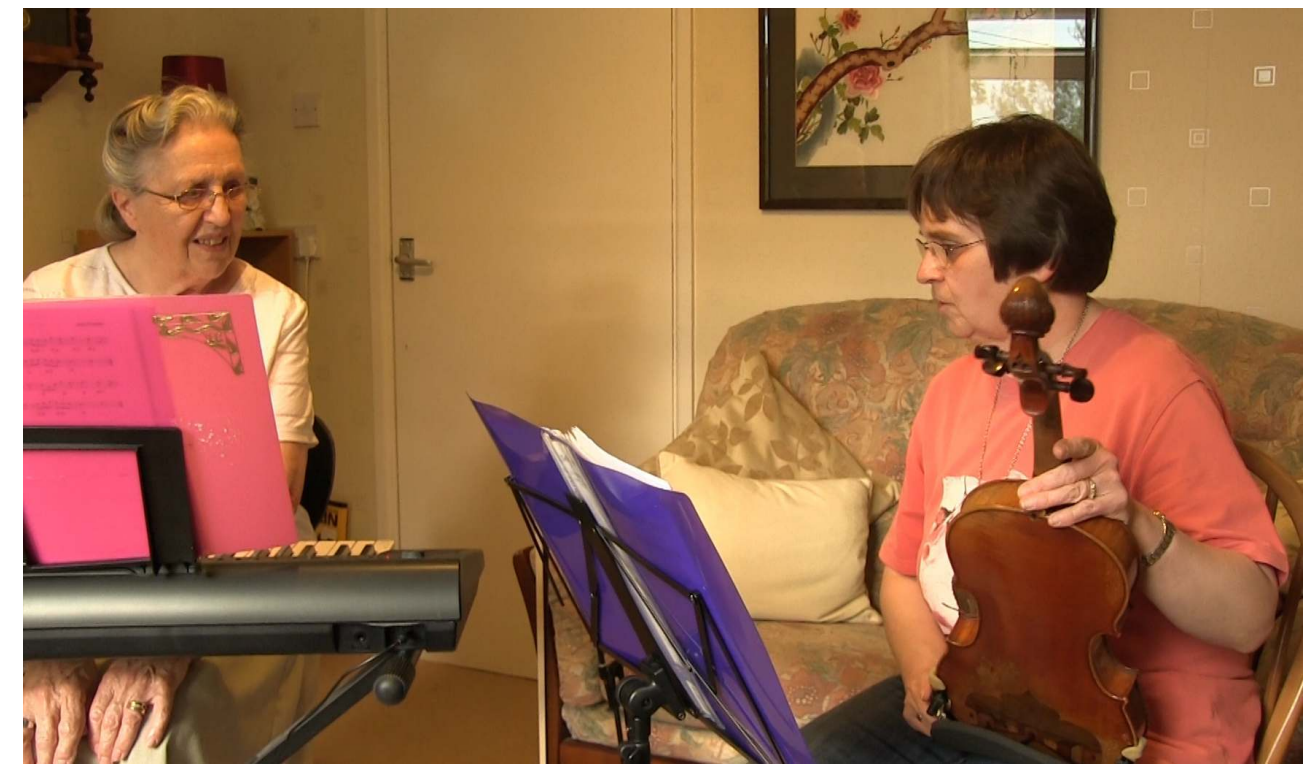

Barbara's living room is transformed into a rehearsal space

Photo by Andrew Stevenson

The film's soundtrack further demonstrates the importance of acoustic spaces for strengthening bonds. Sound adds an acoustic, contextual layer to the experiences of friendship. Listen, for example, to the intense pranayama (breathing) that fills the room and provides the constant soundtrack to Louise and Anne's friendship (Chapter 1). Listen to the teacher calling the Scottish dance and the dancers' steps (Chapter 3). Listen to the radio, the windscreen wipers (Chapter 2) and whirring of bicycle wheels (Chapter 4) that are the soundtracks for Amy, Laura, Andrew and Zara. 


\section{Conclusions and Discussion}

68 (Tillmann-Healy 2001). In using film, we have intended to show friendship bonds through
image, sound, embodiment and emplaced context - as well as talk. These strategies enabled the collection of rich, multisensory data that have highlighted four themes. It is argued here that the present research has shown friendships to be practice-based, suffuse, routinized, and emplaced in nature. We argue that these themes highlight similarities between friendship and other practice-based, suffuse, routinized interpersonal relations, such as kinship and more institutional relations.

Out study resonances with the work of other researchers, including kin-based research of earlier anthropology, yet also raises further issues for the study of friendship itself. Our first theme, emphasizing friendship as a practice based phenomenon, takes us beyond Rawlins (1992) definition of friendship as primarily a means of support and care. Rather, like Tillman (2015), the friendships explored here depended on routine activity. Other researchers have noted varying levels of friendship, from simple, single activity bonds, to multi-stranded relationship (Heaphy and Davies 2012, Shepard 2014). The suffuse nature of the bonds we explored (our second theme) illustrates friendship as being multistranded. However, we acknowledge that this may have been partly due to our recruiting of pairs of friends through our connections with wider organizations (musical, voluntary, occupational). Likewise, the routinized (weekly or daily) meetings that these groups involve may have led to our finding about the routine nature of friendship bonds (theme three), and in turn to neglect another characteristic of friendship that has been noted elsewhere; namely, its sporadic, life-event based nature (Cherry 1996), or indeed its relationship with specific causes or activist campaigns (Shepard 2014). Of all the four themes yielded by our exploration of friendship bonds, the fourth, concerning spaces of friendship, is perhaps the one which has been less well researched in previous friendship studies. We learned that our predominantly female friendship pairs transformed spaces (often physically) into places of affiliation where bonds were enacted. Friendship itself emerges here as a way of endowing spaces with meaning. In this sense, dynamic practices (yoga, dance, driving), transform spaces into sites if meaning and empowerment (Cresswell 2004). It would be interesting for future researchers to explore the emplaced nature of male friendship, and whether such similar transitions are common or required. Equally, it would be interesting to develop the work of Bunsell (2013), who used ethnographic methods to explore the disputed spaces of shared gender gymnasia in relation to female bodybuilder identities. We could ask how shared gender spaces relate to the formation of friendships.

Turning now to the method, we argue that filmed friendship ethnography brings three additional attributes to the project, all of which are suited to the study of friendship.

71 Firstly, working with participants who were known to the lead researcher has enabled access to shared, equal status friendship practices that enhanced exploration of the central element of the research; friendship. Thus, the fieldwork was conducted within and alongside the practices of hanging out, commuting, sharing food, enjoying music and doing voluntary work, all of which enabled the lead researcher to straddle boundaries that might otherwise have separated him from his participants' everyday routines. 
Working with familiars certainly facilitated a level of rapport and acceptance that would have been more challenging to achieve, had such familiarity been absent.

Secondly, we argue that combining friendship and fieldwork brings benefits for research participants since it infuses fieldwork with the reciprocal ethic of friendship, rather than requiring participants to give up time and provide data without any intrinsic reward. Through their engagement in friendship ethnography, participants can come to be heard, known, understood, in ways that can be beneficial to all concerned. Engagement in longterm friendship-ethnography can yield new ways of thinking, feeling and relating that can lead to deepening understanding of one's own relationships and practices. Here Anne reveals how she benefited from the research experience:

Anne: It was really interesting to see myself practising yoga, so in terms of the finished result it was really lovely to see it and I really like the way you did it.

Amy here explains how she benefitted from taking part in research:

Amy: As participants in research, we often don't have an opportunity to meet the researchers running the research project, and sometimes never see the finished paper or findings. With this project, I knew exactly how my partnership would contribute to the overall project and how the findings would be disseminated. I think (the researcher's) presence actually enabled me to relax and act naturally-it was fitting that a film about friendship was being researched by my friend.

74 Thirdly, the use of ethnographic film enables the dissemination of research outputs to a wider audience. By producing a documentary film about friendship bonds and practices, the authors have been able to reach a wider public ${ }^{1}$ with the work, than would have been possible had the work been exclusively disseminated in print. At a recent public screening the following audience feedback suggested that the film provided a way a knowing that can supplement more traditional academic outputs

"It captured well the intimacy of friendship and the variety of friendships we have."

"Very much demonstrated the power of ethnographic film making in social science research."

"I'm delighted to see ethnographic filmmaking being useful to psychology."

(Anonymous audience feedback 2015)

To conclude, we consider potential limitations facing the ethnographic researcher who conducts fieldwork within the context of the ethics of friendship.

Firstly, whilst striving to maintain existing friendship relationships there remains a professional obligation to offer a full account to participants. Such pitfalls are characteristic of the more equal power balance that exists in friendship ethnography, compared with more traditional fieldwork methods. The equity of power and heightened reciprocity of friendship ethnography are exemplified by an obligation to return outputs to the participants for critique. Tillman (2015), in her research with LGBT communities, took her writings back to her community of study for comment. Likewise, during the making of HWKE, friendship pairs were offered the opportunity to attend formative screenings and offer feedback, yielding edits to the film. Treating participants with the ethic of friendship, an ethics of care involves listening to suggestions and concerns with a high degree of compassion.

Second, we note the challenge of maintaining two modes of communication (researcher and friend). Negotiating boundaries is part of all human relations, including research 
related-based ones (Frank 2005). Keeping too much distance can compromise rapport. Too much proximity can endanger the research by producing a merger with a participant. Historically, researchers and participants in social science have been knottily entangled (Powdermaker 1970). Indeed, the very claim of a researcher to investigate and write about an 'other' person is to deny, rather than engage with, hyphens of intersubjectivity that bind us all together. We argue here that it is beneficial to acknowledge and work this hyphen by stepping across the line that divides us from our research participants. We concur with Fine (1998), who argues that operating overtly across boundaries between researchers and participants yields rich data.

Total commonality of experience between researcher and researched can never be achieved, even within friendships (Allen-Collinson 2012). However, when an appropriate balance is achieved the friendship ethnography method can potentially challenge hierarchical separations between researchers and participants (Tillman-Heally 2003), facilitate dialogic research relationships (Simon 2013), and produce rich data in an atmosphere of empathy and reciprocity. In this paper, the existing friendships between the researcher and friend-participants (still ongoing) arguably produced a valuable, widely accessible output, in the form of a publically available film. We argue here that our research project contributes to the existing body of friendship research (Cherry1996, Tillman-Healy 2001, Owton and Allen-Collinson 2014, Shepard 2014) in that by exploring friendship practices among friends, and engaging with these practices using interviews and film, we are able to build an emplaced, multisensory portrait of inter-subjectivities from a position that is located within those entanglements, amidst an ethic of care.

\section{BIBLIOGRAPHY}

\section{Books and articles}

Ager, M. 1996. The Professional Stranger An Informal Introduction to Ethnography, London: Academic Press.

Bakhtin, M. 1986. Speech Genres and Other Late Essays. Austin, TX: University of Texas Press.

Beer, B. and D. Gardner. 2015. Friendship, Anthropology of. In International Encyclopedia of the Social \& Behavioral Sciences. James D. Wright (editor-in-chief), 2nd edition, Vol 9. pp. 425431.0xford: Elsevier.

Braun, V. and V. Clarke. 2006. Using Thematic Analysis in Psychology. Qualitative Research in Psychology 3(2): 77-101.

Bunsell, T. 2013. Strong \& Hard Women. London: Routledge.

Butler, T. 2007. Memoryscape: How Audio Walks Can Deepen Our Sense of Place by Integrating Art, Oral History and Cultural Geography. Geography Compass 1: 360-372.

Carrier, J. 1999. People Who Can Be Friends: Selves and Social Relationships. In The Anthropology of Friendship. S. Bell and S. Coleman, S. eds. Pp. 21-38. Berg, Oxford. 
Coleman, S. 2010. Making Friendship Impure: Some Reflections on a (Still) Neglected Topic. In The Ways of Friendship: Anthropological Perspectives. A. Desai and E. Killick eds. Pp. 197-205. Berghahn, Oxford,

Desai, A. and E. Killick eds, 2010. The Ways of Friendship: Anthropological Perspectives. Berghahn, Oxford.

Cherry, K. 1996. Ain't No Grave Deep Enough. Journal of Contemporary Ethnography 25(1): 22-57.

Cresswell, T. 2004. Place: A Short Introduction. London: Blackwell.

Fausto, C. 2012. The Friend, the Enemy, and the Anthropologist: Hostility and Hospitality Among the Parakanã (Amazonia, Brazil). Journal of the Royal Anthropological Institute 18(1): 196-209.

Fine, M. 1998. Working the Hyphens: Reinventing Self and Other. In The Landscape of Qualitative Research: Theories and Issues. N. K. Denzin and Y. S. Lincoln eds. Pp. 130-155. Thousand Oaks: Sage Firth, R. 1999. Preface. In The Anthropology of Friendship. S. Bell and S. Coleman eds. Pp. xi-xv. Berg, Oxford.

Frank. A. 2005. What Is Dialogical Research and Why Should We Do It? Qualitative Health Research 15(7): 964-74.

Geertz, C. 1973. The Interpretation of Cultures. New York: Basic Books.

Gilligan, C. 2008. Moral Orientation and Moral Development. In The Feminist Philosophy Reader. A. Bailey and C. Cuomo eds. Pp. 46-57. New York: McGraw-Hill.

Green, E. 1998. Women Doing Friendship: An Analysis of Women's Leisure as a Site of Identity Construction, Empowerment and Eesistance. Leisure Studies 17(3): 171-185.

Hanson, S, and G. Pratt. 1995. Gender, Work and Space. London: Routledge.

Heaphy, B. and K. Davies. 2012. Critical Friendships. Families, Relationships and Societies 1(3): 31126.

Held, V. 2006. The Ethics of Care: Personal, Political, Global. Oxford: Oxford University Press.

Killick, E. 2009. Ashéninka Amity: A Study of Social Relations in an Amazonian Society. Journal of the Royal Anthropological Institute 15(4): 701-718.

Langdridge, D. and G. Hagger-Johnson. 2013. Introduction to Research Methods and Data Analysis. $3^{\text {rd }}$ edition. London: Pearson.

Leyton, E. ed. 1974. [1970] The Compact: Selected Dimensions of Friendship. Institute of Social and Economic Research, Memorial University of Newfoundland, Canada.

Marshall, M. 1977. The Nature of Nurture. American Ethnologist 4(4): 643-662.

MacDougall, D. 2006. The Corporeal Image: Film, Ethnography and The Senses. Princeton: Princeton.

Owton, H. and J. Allen-Collinson. 2014. Close But Not Too Close: Friendship as Method(ology) in Ethnographic Research Encounters. Journal of Contemporary Ethnography 43(3): 283-305.

Pahl, R. and L. Spencer. 2004. Personal Communities: Not Simply Families of "Fate"or "Choice". Current Sociology 52(2): 199-221.

Paine, R., 1969. Search of Friendship: An Exploratory Analysis in 'Middle-Class' Culture. Man (NS) $4,504-524$. 
Paine, R. 1974. An Explanatory Analysis of „Middle-Class" Culture. In The Compact: Selected Dimensions of Friendship. E. Layton ed. Institute of Social and Economic Research, Memorial University of Newfoundland, Canada.

Pink, S. 2007. Doing Visual Anthropology. London: Sage.

Pitt-Rivers, J. 1973. The Kith and the Kin. In The Character of Kinship. J. Goody ed. Pp. 89-105. Cambridge University Press, Cambridge.

Powdermaker, H. 1967. Stranger and Friend: The Way of an Anthropologist. London: Norton.

Rawlins, W. 1992. Friendship Matters: Communication, Dialectics, and the Life Course. New York: Aldine de Gruyter.

Rivoal, I. and N. Salazar. 2013. Contemporary Ethnographic Practice and the Value of Serendipity. Social Anthropology 21(2): 178-185.

Roseneil, S. and S. Budgen. 2004. Editorial Introduction: Beyond the Conventional Family. Current Sociology 52(2): 127-134.

Shepard, B. 2014. Community Projects as Social Activism: From Direct Action to Direct Services. Thousand Oaks, CA: Sage.

Simon, G. 2013. Relational Ethnography: Writing and Reading in Research Relationships. Forum Qualitative Sozialforschung/Forum: Qualitative Social Research 14(1): 1-13.

Silver, A. 1989. Friendship and Trust as Moral Ideals: An Historical Approach. European Journal of Sociology 30(2): 274-297.

Spradley, J. 1979. The Ethnographic Interview. Fort Worth, Tex. Harcourt Brace Jovanovich College Publishers.

Tillman-Healy, L. 2001. Between Gay and Straight: Understanding Friendship Across Sexual Orientation. Walnut Creek: Alta Mira.

Tillmann, L. 2015. Friendship as Method. In Solidarity: Friendship, Family, and Activism Beyond Gay and Straight. L. Tillmann ed. Pp. 287-319.New York: Routledge.

Werking, K. 1997. We're Just Good Friends: Women and Men in Nonromantic Relationships. New York: Guilford Press.

Whyte, W. 1993. Street Corner Society: The Social Structure of an Italian Slum. Chicago, IL: University of Chicago Press.

Winlow, S. and S. Hall 2009. Living for the Weekend: Youth Identities in North East England. Ethnography 10(1): 91-113.

Young, M. and P. Willmott 1961. Family and Kinship in East London. Harmondsworth: Penguin.

Films

Stevenson, Andrew. 2015. How We Know Each Other. 30 min.

Stevenson, Andrew. 2015. How We Know Each Other - Trailer. 1 min. https://vimeo.com/130013072

(accessed November 28, 2017) 


\section{NOTES}

1. How We Know Each Other was screened as part of the UK Economic Social Research Council Festival of Social Science in, in Manchester, England, November 2015, and at Days of Ethnographic Film, Ljubljana, Slovenia, March 2017

\section{ABSTRACTS}

This paper presents that argument that by combining the methods of friendship ethnography and visual ethnography, friendship itself reveals itself to be a practice-based, suffuse, routinized and emplaced phenomenon. We have used film and interviews to explore the practices that cement friendship bonds among four friendship pairs. In exploring practices and spaces that bind friendship pairs, research was undertaken with participants with whom the primary researcher and filmmaker is already acquainted to varying degrees of intimacy. Situating the research among friends, treating participants according to the ethics of friendship, draws us closer to an understanding of the nature of their bonds. The use of documentary film as a sensory practice that documents practice more vividly than verbal accounts alone can, used alongside friendship ethnography, draws the research closer to the non-verbal aspects of friendships that epitomize intimacy. Our close encounters with these pairs, enhanced by the medium of film, enable us to argue that friendship itself is a practice which is founded on something done (practice-based), embedded in wider social networks (suffuse), enhanced by regular contact (routinized) and contextualized in space (emplaced).

Cet article aborde l'idée qu'en combinant les méthodes ethnographiques fondées sur l'amitié et l'ethnographie visuelle, l'amitié se révèle être un phénomène avéré et systématique qui induit et influe directement sur cette pratique. Nous avons utilisé des films et des entretiens pour explorer les pratiques qui soudent les liens amicaux entre 4 pairs d'amis. En explorant les pratiques et les espaces qui concrétisent ces liens d'amitié, les recherches furent menées avec des participants avec qui le chercheur cinéaste a des liens d'amitié à des degrés d'intimité différente. En situant la recherche autour d'amis, tout en abordant les participants en fonction de valeur éthique de l'amitié, cela nous a permis d'être plus proche de la compréhension naturelle des liens qui les unissent. En juxtaposant le film documentaire, pratique sensorielle qui raconte d'une manière beaucoup plus vivante que ne pourrait le faire les seules descriptions verbales, conjointement avec l'ethnographie amicale cela a permis au chercheur d'accéder aux domaines non-verbaux qui illustrent l'amitié. Ces rencontres, enrichies par la présence d'un dispositif filmique, nous permettent d'avancer que l'amitié par elle même est un savoir-faire qui est fondé sur une pratique (méthode d'apprentissage) incorporée dans un contexte social plus large (imprégnation) soutenu par des contacts réguliers (systématisation) et contextualisé dans un espace donné (situation).

Este artículo presenta el argumento de que al combinar los métodos de la etnografía de la amistad y la etnografía visual, la amistad misma se revela como un fenómeno inmersivo, "empapado" y localizado, basado en la práctica,. Hemos utilizado películas y entrevistas para 
explorar las prácticas que consolidan los lazos de amistad entre cuatro parejas de amistades. Al explorar las prácticas y los espacios que unen las parejas de amigos, se realizó una investigación con participantes con quienes el investigador principal y el cineasta ya tenían diversos grados de intimidad. Situar la investigación entre amigos, tratar a los participantes de acuerdo con la ética de la amistad, nos acerca a la comprensión de la naturaleza de sus vínculos. El uso del documental como una práctica sensorial que documenta la práctica de manera más vívida que las narraciones verbales, usada junto con la etnografía de la amistad, acerca la investigación a los aspectos no verbales de las amistades que singularizan la intimidad. Nuestros encuentros cercanos con estas parejas, realzados por el medio cinematográfico, nos permiten argumentar que la amistad misma es una práctica que se basa en algo hecho (basado en la práctica), incrustado en redes sociales más amplias (inmersión), realzado por contacto regular ( empapado) y contextualizado en el espacio (localizado).

\section{INDEX}

Palabras claves: amistad, etnografía, visual, documental, localizado, práctica

Mots-clés: amitié, ethnographie, visuel, documentaire, contexte, pratique

Keywords: friendship, ethnography, visual, documentary, emplaced, practice

\section{AUTHORS}

\section{ANDREW STEVENSON}

Manchester Metropolitan University

Andrew's research focuses on the use of diverse qualitative methods for the exploration of relationality. He has used sensory ethnography, friendship ethnography and documentary film in his research into the relationships between people and places.

a.stevenson@mmu.ac.uk

\section{REBECCA LAWTHOM}

Manchester Metropolitan University

Rebecca is a professor of community Psychology, an approach which has a strong value base. She teaches community psychology and qualitative methods. She is a feminist and also leads a Centre on Social Change and Community Well Being. Her work engages with participative and collaborative research with those marginalised by the social system. She writes into disability, feminism and migrant literature working qualitatively and in solidarity.

r.lawthom@mmu.ac.uk 